\title{
A Note about Currencies
}

\section{Germany}

1 mark (about \$0.25)

100 pfennigs

1 groschen

1 taler

10 pfennigs

3 marks

Austrian Empire

1 guilder (about 2 marks or $\$ 0.50$ ) 100 kreuzer

U.S. dollar equivalents refer to the pre-World War I exchange rates and should be considered only a rough guide. There is no meaningful way to measure any of these values against the buying power of today's dollar. The reader is referred to the discussion of wages and expenses in the Introduction, as well as to the context of each individual autobiographical selection. 
This page intentionally left blank 